\title{
Parents' expectations and perceptions concerning the provision of communication aids by the Communication Aids Project (CAP)
}

Caroline Newton ${ }^{1}$, Jannet A. Wright ${ }^{2}$, Michael Clarke ${ }^{1}$, Chris Donlan ${ }^{1}$, Claire Lister $^{3}$ and Jasmina Cherguit ${ }^{4}$

${ }^{1}$ Department of Human Communication Science, University College London, Chandler House 2 Wakefield Street, London WC1N 1PF

${ }^{2}$ School of Allied Health Sciences, Faculty of Health and Life Sciences, De Montfort University, The Gateway, Leicester LE1 9BH

${ }^{3}$ Conference Services, The Institute of Child Health, 30 Guilford Street, London WCIN 1EH

${ }^{4}$ Redford Lodge Psychiatric Hospital, 15 Church Street, Edmonton, London N9 9DY

Address for correspondence:

Dr. Caroline Newton

Department of Human Communication Science

University College London

Chandler House

2, Wakefield Street

London WC1N 1PF

Email caroline.newton@ucl.ac.uk

Tel: 020-7679-4222

Fax: 020-7713-0861 


\section{Abstract}

This paper reports findings from part of an evaluation study of the Communication Aids Project (CAP), a government-funded project in England which provided communication aids to schoolaged children. The paper focuses on parents' views of the CAP process and the impact of the aid. Fourteen parents were interviewed twice over the telephone: once before or just as their children received communication aids, and again six to eight weeks later. Parents expressed satisfaction with the impact of the aid on their children's lives, and showed they had realistic expectations concerning potential short- and long-term benefits. They raised two main concerns regarding the provision of aids, namely the timescale involved and accessing accurate information and advice. 


\section{Introduction}

It is widely recognised that parents have a significant role to play - in partnership with health and education professionals - in raising level of achievement of their children with special educational needs (SEN). The SEN Code of Practice (Department for Education \& Skills, 2001) highlights the role of parents in ensuring children's needs are best met and notes that 'the work of professionals can be more effective when parents are involved and account is taken of their wishes, feelings and perspectives on their children's development' (p. 16). This has been found to be especially true for the group of children with SEN who use communication aids to support speaking and writing. Researchers such as Angelo, Jones and Kokoska (1995) note that families have a key role in the successful introduction and subsequent use of a communication aid, and that professionals working with such children need to show understanding and sensitivity towards the needs, priorities and concerns of parents. Cress (2004) stresses the importance for practitioners of noting the views of parents and working with them in intervention, as they bring valuable - and accurate insight and experience.

Children using communication aids include those for example who have difficulties with written language and those who need an aid to assist them with face-to-face communication. These may be children with visual or hearing impairments, those who have been identified as having dyslexia, and children who have physical disabilities such as Cerebral Palsy.

This paper reports some of the findings of an independent evaluation study of the Communication Aids Project (CAP) (Wright et al., 2004). CAP managed a process of referral, assessment and provision of additional equipment and technology for pupils in England who have significant communication difficulties: understanding language, communicating verbally and/or using written communication. CAP worked in partnership with English Local Education Authorities (LEAs) to provide communication aids, offering 'value-added' funding which supplemented but did not replace LEA funding for the provision of aids. 
CAP was operational between April 2002 and March 2006, and was funded by the Department for Education and Skills (DfES) by the British Educational and Communications Technology Agency (BECTA). It was established initially through funds made available by the UK Treasury's Capital Modernisation Fund. A grant of $£ 10 \mathrm{~m}$ was awarded over three years ending March 2004 (£1.5m, $£ 3.5 \mathrm{~m}$, £5m respectively). Further funding was secured from the DfES to extend the project until March 2006.

CAP supports the provision of a wide variety of communication aids. These can vary from complex voice output communication aids (VOCAs) - or Speech Generating Devices - to relatively simple single message speech output devices. They can also include portable writing aids such as laptops with a range of specific software options, monitors, printers (including Braille printers) and mounts and switches.

Applications for CAP aids were made primarily by professionals working with children such as education staff and Speech and Language Therapists, and to a lesser extent by parents. Once the application had been processed children were assessed via one of the six CAP Centres (Abilitynet, ACE North, ACE Oxford, Deaf Children's Communication Aids Project (DCCAP), London CAP and SCOPE). At assessment children were recommended a communication aid and training for the child, parents and education staff on the use the aid. CAP also co-ordinated the subsequent ordering and delivery of aids.

The introduction of CAP was a significant new development in the provision of communication aids to school-aged young people. Traditionally, it has been necessary for families and professionals to explore funding opportunities through education, health, social services and charities. Where some funding sources have been made available, they may not have been obviously accessible, with professionals and families being required to research a range of options. The introduction of CAP was aimed to address this issue, helping 'pupils who have communication difficulties by providing technology to help them access the curriculum and interact with others and support their transition to post-school provision' (CAP website). 
A key part of the CAP evaluation study was a set of telephone interviews with parents of children receiving CAP-funded communication aids. These interviews covered the parents' perspectives on the provision of aids via CAP and the impact of the aid on issues relating to communication, school work and interpersonal relationships. The views of parents are important in evaluating the success of the service provided by CAP and provide useful information for those working with children who use communication aids.

There is a growing body of work on parents' views on health and education provision for children with speech and language problems, and specifically those who use communication aids. Much of the research reported in the literature highlights similar issues for the parents.

The arrival of a communication aid can result in a significant change to family life. Angelo (2000) comments on the resulting increased responsibility for parents. In her study, Angelo conducted a survey with 114 parents of communication aid users in Pennsylvania in the United States and found that over half of the respondents felt that their roles and responsibilities had increased as had demands on their time. Families must also adapt to changes in interaction patterns involving their children, and though parents want their children to communicate effectively, with the busyness of family life many may find it easier to continue to make use of old communication strategies than adapt to a new system (Sweeney, 1999). Ko et al. (1998:202) also note that parents of VOCA users 'may continue to rely for speed on asking their children questions requiring yes/no answers'. McCord \& Soto (2004) report the perceptions of AAC of four Mexican-American familes where AAC was being used by a child. Parents did not find the devices useful for interactions at home and preferred to not to use them (in part because of cultural preferences for speed and intimacy). However, the parents were keen on AAC use at school for educational purposes.

Despite these changes, parents appear to be realistic concerning their expectations of changes to their child's communication skills, and have much useful information to provide on their child's 
competence and limitations in communication and social interactions (Goldbart \& Marshall, 2004:200).

Goldbart and Marshall interviewed eleven parents of children who were in the early stages of using a formal AAC (Augmentative and Alternative Communication) system in their study of parents' perspectives regarding AAC use. The parents commented on the frustrations they had experienced with the system of funding in place in England at the time. Respondents had often found themselves having to arrange for funding for a communication aid or funding it themselves, and commented that they felt burdened by the extra - indirect - costs associated with the aid, such as adapting the home environment.

Accessing information is another issue for parents of children with SEN, including information on identifying and accessing resources (Lindsay \& Dockrell, 2004; Goldbart \& Marshall, 2004). Parents feel that they are not provided with enough information to enable them to make informed decisions regarding their children's education and health needs (Law \& Elias, 1996; Paradice \& Adewusi, 2002). When discussing literacy issues concerning children with physical disabilities, Pierce \& McWilliams (1993) highlight the fact that lack of information can adversely affect parents' ability to develop realistic expectations for their children's future development. Researchers have also reported sometimes considerable differences in the availability of information between children in mainstream settings and those in special schools, where parents of the latter feel better informed about their child's needs and progress (Lindsay \& Dockrell, 2004).

A frequent theme in the literature on parents' perspectives in the area of SEN generally, and communication aid provision specifically, is their perceived need to be assertive in order to obtain the best provision for their children. Parents use terms such as 'fight', 'battle' and 'struggle' to describe their experiences, and parents' efforts on behalf of their children are not always successful (Pinkus, 2005). Paradice \& Adewusi (2002) carried out focus group discussions with parents of children with speech and language difficulties. Those involved felt that the level of provision and support for their child was directly related to how hard the parent was able to fight for 
it. The parents involved in Goldbart \& Marshall's (2004) study report the need to be 'pushy' not only in obtaining a communication aid for their child, but also in the 'on-going struggle to keep professionals active on their child's behalf' (p. 206). This group also mentioned their need to take responsibility for training, programming and equipment associated with the aid.

Set against all these issues for parents is the vital role that they play in the introduction and implementation of the communication aid. Jones, Angelo \& Kokoska (1998) note that if parents are not fully and appropriately involved in the process there is a greater risk of the aid being abandoned. Therefore, given the recognised significance of the family's involvement in helping to ensure the success of a communication aid's introduction and utilisation, it is important for professionals working with communication aid users to be aware of parents' perceptions and expectations - in relation to the services provided to their children and to the potential of the aid and its impact on a child's life.

Much of the research evidence noted above was carried out either in the U.S. or in Britain under the funding and provision system in place before the introduction of the Comunication Aids Project. The CAP evaluation study therefore has much useful information to add on what is known about support for those using communication aids under this new system of funding, including the perceptions and expectations of parents whose children are receiving aids. More specifically, parents involved in this study were asked about their expectations regarding the aid, the impact of the aid, and their experiences of the process of CAP service delivery.

\section{Method}

1. The CAP evaluation study

The independent evaluation of CAP was funded by the DfES and is reported in full detail in Wright et al.'s (2004) research report. The evaluation included an analysis of the CAP database which indicated national patterns and processes in referral and provision; an analysis of service costs and use; interviews with staff associated with the management of CAP, assessments and support provided by CAP and LEA contacts; and individual case studies with children with a CAP-funded 
aid, their parents, teachers and Speech and Language Therapists (Wright et al., 2006; Newton at al., in press).

\section{Participants}

The British Educational and Communications Technology Agency (BECTA) held a database of children who had applied to CAP. The database held information on the characteristics and needs of the children and information on each child's assessment. Parents of 1139 children had given permission to BECTA for participation in research. From these anonymised records, the research team selected a sample of children from the six CAP centres. In this way the case studies were representative of the profile of children supported by CAP. BECTA made available to the research team contact information for these children.

This paper reports findings from interviews with fourteen parents of children who were provided with communication aids by CAP. Their children included nine boys and five girls and ranged in age from 7;06 to $16 ; 10$. The children represented a wide geographic spread from Durham to Plymouth and from Cheshire to Kent. Seven children were being educated in mainstream schools, with six attending special schools and one child with provision shared between a special school and a mainstream school. The majority of children (nine) were provided with VOCAs by CAP, four received laptops and CAP provided one child with both pieces of equipment. Diagnoses of the children included cerebral palsy; hearing impairment; dyslexia and learning difficulty. The parents interviewed included eleven mothers and three fathers.

\section{Interviews}

Parents were interviewed by telephone at a pre-arranged convenient time, once before or just as their children received their communication aids (Time 1 interviews), and again in a follow-up interview six to eight weeks after the child had received their aid (Time 2 interviews). All interviews were conducted by one member of the independent CAP evaluation research team. The original sample contained eighteen parents but as four of these had either not received the aids or did not have a functional aid at Time 2, fourteen Time 2 interviews were completed. All participants were 
sent a copy of the interview schedules before the interviews, which were recorded using ${ }^{C T I}$ Pulsar $P C$ telephone and room recorder. The main themes of the interviews are shown in Table 1.

Interviews included open questions (e.g. 'How would you improve the process of being involved with CAP?') and questions requiring the parent to give a response from a closed set of responses such as a Likert scale (e.g. 'How much do you think $X$ will benefit from his/her aid in the next $8-12$ weeks?' Not at all/a bit/a great deal)). Parents were invited to expand on their responses to the latter type of question if desired. All interviews were transcribed for analysis.

\section{INSERT TABLE 1 ABOUT HERE}

4. Analysis of the data

All interviews were transcribed and analysed using a Grounded Theory approach (Strauss \& Corbin, 1998), in which the researcher does not test a hypothesis but seeks to discover from the data which 'theory' best accounts for the findings. In this study, interviews were read and re-read and compared with each other until common core themes emerged.

\section{Findings of the evaluation study ${ }^{1}$}

\section{The impact of the aid}

Half of the parents interviewed post-aid said that the aspect of CAP with which they were most satisfied was the fact that CAP had provided their child with a communication aid. This included parents of children who had previously been using an aid and those who before the provision of this aid had been using low-tech communication systems such as symbol books. One parent described her son's reaction to receiving his aid: 'he kissed the box when it came out of the cupboard'.

Parents reported that their children enjoyed using the aid and they found it easy to use. The patterns of their responses are shown in Figure 1.

\footnotetext{
${ }^{1}$ All names given are pseudonyms.
} 


\section{INSERT FIGURE 1 ABOUT HERE}

With her other one you had to press about ten different buttons to get one little word out... [with the new aid] once you know how to do something it's easy to do it again... and to get out sentences'

'And when we have the [communication aid] it's absolutely brilliant because it's same, generally it's the same like a symbol book, but it's much better, she can use that very easily.'

'He uses it all the time and he never really liked things like communication books or anything like that. But, you know, things like computers and computer games and the communication aid and all the rest of it, it's like, you know, like boys with toys.'

Parents reported that as well as for schoolwork children were using their aids for extra-curricular activities. One parent of a child with profound hearing loss described how her daughter is using the DVD player on her laptop with her friends. Instead of renting videos which do not have subtitles on them, they are now able to rent DVDs which do have subtitles and which the group of friends can all watch on the child's computer.

Another child is using his aid to join in at the chess club at school: 'because he can't be as accurate sometimes as he'd like to be in moving a chess piece, he'll give somebody the location... so somebody knows exactly where he wants his piece moved.' Having a voice output communication aid which also allows him to do written work is enabling another child to correspond with friends via the Internet.

During the Time 2 interview, parents were asked how satisfied they were with the aid. Eleven of the fourteen interviewed said that they were very satisfied. Of the three who were partially satisfied, all were waiting for training on the aid and were aware that their child was not yet using 
the aid as much as they thought possible and two had yet to receive wheelchair mounting for the aid.

a) Use of the communication aid

During the Time 1 interview parents were asked to give details on where and for what activities they anticipated their child would be using their aid. They were given a list of possible locations (e.g. classroom, playground, home) and activities (e.g. talking to the teacher and/or friends, planning work, checking spelling) and selected those they thought would apply. They were given the same list at the Time 2 interview and asked to indicate in which location and for which activities their child was currently using the aid. The full list is given in Appendix 1.

Parents' responses generally reflected the type of aid their child had been recommended, with those receiving VOCAs anticipating that they would be used to 'talk' to others and those receiving laptops anticipating they would be used for school-based written work. When their responses at Time 2 were compared with those given in the Time 1 interview, it was noted that they had accurate expectations regarding the locations in which the aids would be used, and the majority of expectations regarding activities were met at Time 2. Some parents however reported at Time 2 that their child's aid was not being utilised for the number of activities they had anticipated.

Cases where responses at Time 2 were markedly different from expectations at Time 1 were either where a laptop was not yet being used for the full range of written work at school (e.g. for writing answers to school work but not for planning work or taking notes) or where at Time 1 parents had expected that their child might use their new VOCA to talk more with others (including the parents themselves) than they reported at Time 2. Parents reported this was due to factors such as 'getting used to the aid' and the need for more information to be programmed into the aid. One parent commented on the fact that her daughter was only occasionally using the aid to talk to family members: 'we're more switched on to her communication than anybody so it's easier for us to understand what she's trying to say'. 
In contrast to this there were two parents who reported that their child was using their aid for more activities than they had expected. These children were both VOCA users and were using their aid for producing written work, which the parents had not anticipated at Time 1.

b) Interpersonal relationships

Figure 2 shows a summary of the responses of parents at both interviews to statements on the interpersonal relationships their children experienced. They were asked to respond to statements such as ' $X$ enjoys school' and ' $X$ does not have many friends outside school' using a five-point Likert scale, including the categories strongly agree, agree, neither agree nor disagree, disagree and strongly disagree, as well as a 'not applicable' category. The chart shows the frequency of 'strongly agree' and 'agree' responses to the statements at Time 1 and Time 2.

\section{INSERT FIGURE 2 ABOUT HERE}

Parents gave very positive responses to the statements given (note that a low frequency of agreement to the statement 'does not have many friends outside school' indicates a positive response), and there was very little difference between Time 1 and Time 2. Responses were more mixed regarding the number of friends children had outside school. Children with few friends outside school at both Time 1 and Time 2 were of a mixture of ages, in both types of educational setting, with some wheelchair users and others ambulant. All but one of the seven children were VOCA users and four of the children had been diagnosed with Cerebral Palsy.

c) Potential benefits of the aid

Parents were asked at Time 1 how much they thought their child would benefit from his or her aid in the following 8-12 weeks, and in the next year. At Time 2 they were asked about their perception of how much their child had already benefited from the aid and their expectations of long-term benefits. For all of these questions they were asked to select either 'not at all', 'a bit' or 'a great deal'. All parents at both Time 1 and Time 2 thought that their child would benefit a great deal in the long term. Table 2 shows a comparison of level of short-term benefit expected at the 
Time 1 interview and the level of benefit perceived by the parent at the Time 2 interview after the first few weeks of using the aid. Almost all the parents indicated that they anticipated at Time 1 that their child would benefit a great deal in the short term, and that these expectations were not always matched by perceptions at Time 2: five children had not benefited as much from the aid as anticipated.

\section{INSERT TABLE 2 ABOUT HERE}

From the analysis of discussions on the benefits of the communication aids and possible reasons for expectations at Time 1 not being met fully at Time 2, two issues emerged. First, the parents of two VOCA users, children 9 and 13, felt that their children had not gained maximum advantage from the aid partly because the VOCA had not yet been mounted on the children's wheelchairs (a further two children were waiting to receive equipment to enable them to access their aids more easily). One parent commented: '[in the long term] the world's her oyster type thing. Obviously we need to get it mounted so it's there whenever she needs to use it, which is the issue that's outstanding.'

The other parents mentioned that the first two months of use had been a period of 'getting used' to the aid and felt that the aids would become much more beneficial in the long term. For example, CAP has provided one child with a laptop to help him access written language. His parent reported: 'I think his use of it is going to go up over time... particularly when he goes up into senior school next year which is going to require a lot more independent work... the benefit of it now is that he can get used to it so that he can use it well when he moves on to senior school'. Another child has both a new laptop and VOCA: 'I think at the moment it's still early days to say a great deal, but I certainly can see the benefits... give him another year'.

\section{The Communication Aids Project}

In the Time 2 interview parents were asked what they were most and least satisfied with regarding their experiences of CAP. Half of the participants commented that the most satisfactory aspect 
was the provision of the communication aid, with some parents acknowledging that without CAP it would have been very difficult to obtain the appropriate equipment. One parent commented: 'we would never have got the communication aid for Hannah if we hadn't had CAP to go to'. A further three parents highlighted the skills of the professionals (often in multi-professional teams) involved in the assessment for their child's communication aid, and in the training provided on the aid, as the most satisfactory aspect of the CAP process.

These views were also expressed in the Time 1 interviews, in which parents were asked to indicate their level of satisfaction with different aspects of their involvement with the Communication Aids Project. These responses from the Time 1 interview are shown in Figure 3. Parents' views on the assessment and the aid itself were very positive.

\section{INSERT FIGURE 3 ABOUT HERE}

Parents' views on other aspects of the process are not as overwhelmingly positive as those on assessment and the recommendation of aids. The majority of comments on these other aspects focussed on two areas: the timescale of the process and the need for parents to 'chase up' information.

\section{a) Timescale}

When discussing the co-ordination of the services parents' thoughts often turned to the length of time between application and assessment and delivery of the aid. One factor in waiting for assessments is the logistics of gathering a range of professionals together to provide a comprehensive assessment - one of the most satisfactory aspects of the process. It was clear from their responses that some parents were used to waiting for complex pieces of equipment for their child, but for many others this was a new experience. One parent commented: 'I didn't know how long the process would take... but if we'd had some sort of benchmark so I would have known oh well you should have had this equipment by such and such a time'. 
Parents expressed different expectations concerning what would be a reasonable length of time to wait for the delivery of the aid. For example, one parent commented that the speed of delivery was the most satisfactory of CAP; her daughter had waited eight months. Other parents were less satisfied with shorter waiting periods.

b) Information

Participants also expressed dissatisfaction with their own involvement with the CAP process (see Figure 3). They would have appreciated more information on timescale, as mentioned above, and on issues such as insuring the equipment provided. Several parents felt that they had had to be particularly pro-active in gaining information on different aspects of the process, in dealing with problems and incorrect information and ensuring that the aid was delivered with minimum delay. For example, for David the process of receiving a VOCA took a year and during that year his parent had to 'chase up' information on the status of the delivery of the aid, receiving different incorrect - information from people she telephoned. She said 'if I'd known it was going to be this problem, I would have been even more pro-active at the beginning'.

For many parents this is a greater involvement in the process that they feel they should have, especially if they are caring for a child with disabilities. The father of a child with cerebral palsy commented: 'it's not my job, it's not my wife's paid job, it is extra on top of living a life of looking after a disabled child'.

Some parents suggested that a named contact person for the whole process to whom they could turn would be useful. In many cases where a Speech and Language Therapist was involved, it was that professional who took responsibility for doing this. One parent commented: 'I think it probably needs someone to oversee the whole process and be some sort of mediator over the referral, supply and delivery of the thing'.

\section{Discussion}

\section{The impact of the aid}


Data collected from the interviews in this study indicate that participants are aware of and positive about the potential benefits that communication aids can bring their children, whether VOCAs or laptops with specialist software to support written work. Figure 2 shows parents' expectations at Time 1 with regards to location and activities relating to the new aid were met at Time 2 . The remarks that many made when discussing short- and long-term benefits indicate that in most cases their expectations are not unrealistically high: they are aware that the success of the aid depends on a variety of factors such as access to the aid and a useful period of familiarisation. This is in contrast with the findings of Ko et al. (1998), who found that many parents included in their study had unrealistic expectations regarding the improvements that a VOCA can make to a child's communication skills. Parents' expectations in this study may have been influenced by the age of their children (all the children were aged over seven years) and the fact that all but one of them had some experience with a communication system (though for five children this was a lowtech system). Thus the parents had some knowledge on which to base their expectations. Nevertheless, this is encouraging news for those who work with children receiving communication aids. As mentioned above, parents' involvement in and attitudes towards their introduction are key. Realistic expectations and positive perceptions therefore will be helpful in the successful introduction of an aid. Therefore parents already experienced with communication aids may themselves be a useful resource for parents new to this area.

In the cases where perceptions at the Time 2 interview did not match earlier expectations (see Figure 2) this mismatch seemed to be due to one of two factors. First, some laptops were not yet being used for all written activities, which may be due to the child still becoming familiar with the equipment and software. Second, some parents of VOCA users had anticipated that their child's aid would be used to talk to a wider range of individuals (often including themselves) than they reported in the Time 2 interview. While the child is familiarising him or herself with the aid it may still be easier for parents and children to communicate using the strategies that they had become used to before the aid arrived, which is consistent with the findings of Ko et al. (1998) and Sweeney (1999) outlined above. In both scenarios outlined, it seems likely that further time becoming familiar with the aid (in addition to other factors, such as continued encouragement of 
use at school) may increase the activities for which the aid is used, though old communication strategies may still be used successfully. Due to the time restrictions of the CAP evaluation study, of which this study is a part, it was not possible to interview parents more than eight to ten weeks after the aid had been received. A further follow-up study with the same individuals would be useful in order to gauge whether a longer period of familiarisation would have the desired effect for both laptop and VOCA users.

Parents' reported perceptions of their children's interpersonal relationships are positive, indicating that these young people are participating fully in family life and on the whole have established a good network of friends at school. However, some children were reported to have few friends outside school. The timing of the Time 2 interview was such that it would probably be too soon to tell whether the aid would have a long-term impact here. Again, a follow-up study would indicate whether, with increased familiarisation with and use of the aid in different settings, the situation regarding friends outside school (and, to a lesser extent, meeting new people) would change for the better. Work by Jolleff et al. (1992) suggests that this might be the case. In their study of the interaction patterns of a group of children who receiving voice output communication aids, they found that in the long term some users experienced a 'significant boost' in their communication skills, which was especially beneficial in extending their range of conversational partners.

\section{The system of funding and provision}

Parents raised three core issues regarding the system of provision of communication aids they had experienced. Each of these provides a useful pointer for professionals and service providers working with parents within any system of funding and provision.

Parents' indicated high levels of both appreciation of CAP's existence and satisfaction with professionals involved, both at assessment and in training on the communication aids. This is a positive finding, particularly as one of the intentions of CAP has been to develop a large group of skilled personnel who are able to provide support and advice for children with communication difficulties. 
Two particular concerns were highlighted by the participants in this study. The first of these is the need for a realistic indication of how long the process takes, especially post-assessment. Parents acknowledge that the provision of the aid may take time, especially in cases where its set-up is more complicated (for example, where a device such as a joystick or head pointer to enable the child to access the aid or a mounting system on a wheelchair may be needed). There is also variation between parents regarding what constitutes an acceptable waiting period. Despite these facts, those interviewed suggested that a benchmark for a probable timescale (from application to assessment to delivery) for different types of aid would be useful. In addition, assessments could, where appropriate, seek to make recommendations that support in the use of existing technology in school and/or introduce or improve use of low-tech systems. This will provide parents and schools with opportunities to explore the use of alternative forms of communication before the technology is delivered.

The second concern raised by parents here, and which mirrors a key issue highlighted in the literature in this area (e.g. Lindsay \& Dockrell, 2004; Pierce \& McWilliams, 1993), is the difficulty of gaining accurate information on a range of matters, such as delivery and insurance. Many parents were obliged to take responsibility for contacting services to ask for information and advice, and were frustrated by this. Some suggested that an individual such as a key worker would be helpful here. This comment is echoed in recent government recommendations that a lead professional should be identified from the team working with a disabled child and their family (DfES, 2004). Therefore, the identification of a key person to contact at a local level if parents are unsure about an aspect of any future system of provision would be advantageous for parents. This person could be identified at the time of the assessment.

The Communication Aids Project had a finite lifespan and ended in March 2006. However, the Prime Minister's Strategy Unit's (2005) report on 'Improving the life chances of disabled people' indicates that the needs of disabled children should be a priority in future government policy in terms of opportunities and choices in improving their quality of life, including access to necessary 
equipment and providing a key worker to provide support and information for families with high needs. Parents' experiences with CAP therefore provide useful pointers for future arrangements in the provision of communication aids and can indicate how best service providers and professionals can support children receiving communication aids and their families.

\section{References}

Angelo, D.H. 2000: Impact of augmentative and alternative communication devices on families. Augmentative and Alternative Communication 16, 37-47.

Angelo, D., Jones, S. \& Kokoska, S. 1995: A family perspective on AAC: families of young children. Augmentative and Alternative Communication 11, 193-201.

CAP website: http://cap.becta.org.uk (accessed 17 June 2016)

Cress, C. J. (2004). AAC and language: Understanding and responding to parent perspectives. Topics in Language Disorders 24, 28-38.

Department for Education and Skills 2001: Special educational needs: Code of practice. London: DfES.

Department for Education and Skills 2004: Every child matters: next steps. London: DfES.

Goldbart, J. \& Marshall, J. 2004: "Pushes and pulls" on parents of children who use AAC. Augmentative and Alternative Communication 20, 194-208.

Jolleff N., McConachie H., Winyard S., Jones S., Wisbeach A., Clayton C. 1992: Communication aids for children: procedures and problems. Developmental Medicine and Child Neurology 34, 719-30. 
Jones, S., Angelo, D. \& Kokoska, S. 1998: Stressors and family supports: families with children using augmentative and alternative communication technology. Journal of Children's Comunication Development 20, 37-44.

Ko, M. L. B., McConachie, H. \& Jolleff, N. 1998: Outcome of recommendations for augmentative communication in children. Child: Care, Health and Development 24, 195-205.

Law, J. \& Elias, J. 1996: Trouble talking: A guide for parents of children with speech and language difficulties. London: Jessica Kingsley.

Lindsay, G.A. \& Dockrell, J.E. 2004: Whose job is it? Parents' concerns about the needs of their children with language problems. Journal of Special Education 37, 225-236.

McCord, M.S., \& Soto, G. (2004). Perceptions of AAC: An ethnographic investigation of MexicanAmerican families. Augmentative and Alternative Communication 20, 209-227.

Newton, C., Wright, J.A., Clarke, M., Donlan, C., Lister, C. \& Cherguit, J. (in press). Supporting children with communication aids in transition: the perspective of children and adults involved with the Communication Aids Project (CAP). Support for Learning

Paradice, R. \& Adewusi, A. 2002: 'It's a continuous fight isn't it?': Parents' views of the educational provision for children with speech and language difficulties. Child Language Teaching \& Therapy 18, 257-288.

Pierce, P. \& McWilliam, P. 1993: Emerging literacy and children with severe speech and physical impairments: Issues and possible intervention strategies. Topics in Language Disorders 13, 47-57. 
Pinkus, S. 2005: Bridging the gap between policy and practice: adopting a strategic vision for partnership working in special education. British Journal of Special Education 32, 184-187.

Prime Minister's Strategy Unit 2005: Improving the Life Chances of Disabled People. London: Strategy Unit.

Strauss, A.L., \& Corbin, J. 1998: Basics of qualitative research: techniques and procedures for developing grounded theory. London: Sage.

Sweeney, L.A. 1999: Moving forward with families: perspectives on AAC research and practice. In F.T. Loncke, J. Clibbens, H.H. Arvidson \& L.L. Lloyd (eds) Augmentative and alternative communiation. New directions in research and practice. London: Whurr.

Wright, J.A., Newton, C., Clarke, M., Donlan, C., Lister, C. \& Cherguit, J. (2006). Communication aids in the classroom: the views of education staff and speech and language therapists involved with the Communication Aids Project (CAP). British Journal of Special Education 33, 25-32

Wright, J., Clarke, M., Donlan, C., Lister, C., Weatherly, H., Newton, C., Cherguit, J., \& Newton, E. (2004). Evaluation of the Communication Aids Project (CAP). (DfES Research Report RR580). London: DfES. 
Table 1. Themes of Time 1 and Time 2 interviews with parents.

\begin{tabular}{|c|c|}
\hline Interview at Time1 & Interview at Time2 \\
\hline $\begin{array}{l}\text { Background information } \\
\text { - Details on the assessment for the aid } \\
\text { - Type of aid recommended } \\
\text { - Previous communication system used and perceived reasons } \\
\text { for change of system }\end{array}$ & $\begin{array}{l}\text { Background information } \\
\text { - Perception of child's general progress with aid so far }\end{array}$ \\
\hline $\begin{array}{l}\text { Use of the aid } \\
\text { - Anticipated use of aid (e.g. talking to others, school work) } \\
\text { - } \text { - Expected short- and long-term benefits to the child } \\
\text { - Views on the child's current interpersonal relationships at home } \\
\text { and school }\end{array}$ & $\begin{array}{l}\text { Use of the aid } \\
\text { - Current use of aid } \\
\text { - Training received on aid } \\
\text { - Benefits of aid so far and expected long-term benefits } \\
\text { - Satisfaction with the aid } \\
\text { - Views on the child's current interpersonal relationships at home } \\
\text { and school }\end{array}$ \\
\hline $\begin{array}{l}\text { Communication Aids Project } \\
\text { - Satisfaction with the CAP process }\end{array}$ & $\begin{array}{l}\text { Communication Aids Project } \\
\text { - Satisfaction with the CAP process } \\
\text { - Suggested improvements to CAP }\end{array}$ \\
\hline
\end{tabular}


Table 2. Parents expectations and perceptions of the short-term benefits of communication aids

\begin{tabular}{|c|c|c|c|c|}
\hline Child & $\begin{array}{l}\text { Age at } \\
\text { Time } 1\end{array}$ & Type of aid & $\begin{array}{l}\text { Time 1: } \\
\text { benefit in next 8-12 weeks }\end{array}$ & $\begin{array}{l}\text { Time 2: } \\
\text { benefit so far }\end{array}$ \\
\hline 1 & 7.06 & VOCA & A great deal & A great deal \\
\hline 2 & 7.10 & VOCA & A great deal & A great deal \\
\hline 3 & 10.01 & VOCA & A great deal & A great deal \\
\hline 4 & 10.11 & VOCA & A bit & A bit \\
\hline 5 & 11.07 & VOCA & A great deal & A bit \\
\hline 6 & 11.09 & Laptop & A great deal & A bit/a great deal \\
\hline 7 & 12.00 & Laptop & A great deal & A great deal \\
\hline 8 & 12.03 & VOCA \& laptop & A great deal & A bit/a great deal \\
\hline 9 & 12.03 & VOCA & A great deal & A bit \\
\hline 10 & 12.11 & Laptop & A great deal & A great deal \\
\hline 11 & 13.00 & Laptop & A bit/a great deal & A bit/a great deal \\
\hline 12 & 14.02 & VOCA & A great deal & A great deal \\
\hline 13 & 15.07 & VOCA & A great deal & A bit \\
\hline 14 & 16.10 & VOCA & A great deal & A great deal \\
\hline
\end{tabular}


Figure 1. Parents' views on their child's use of the aid

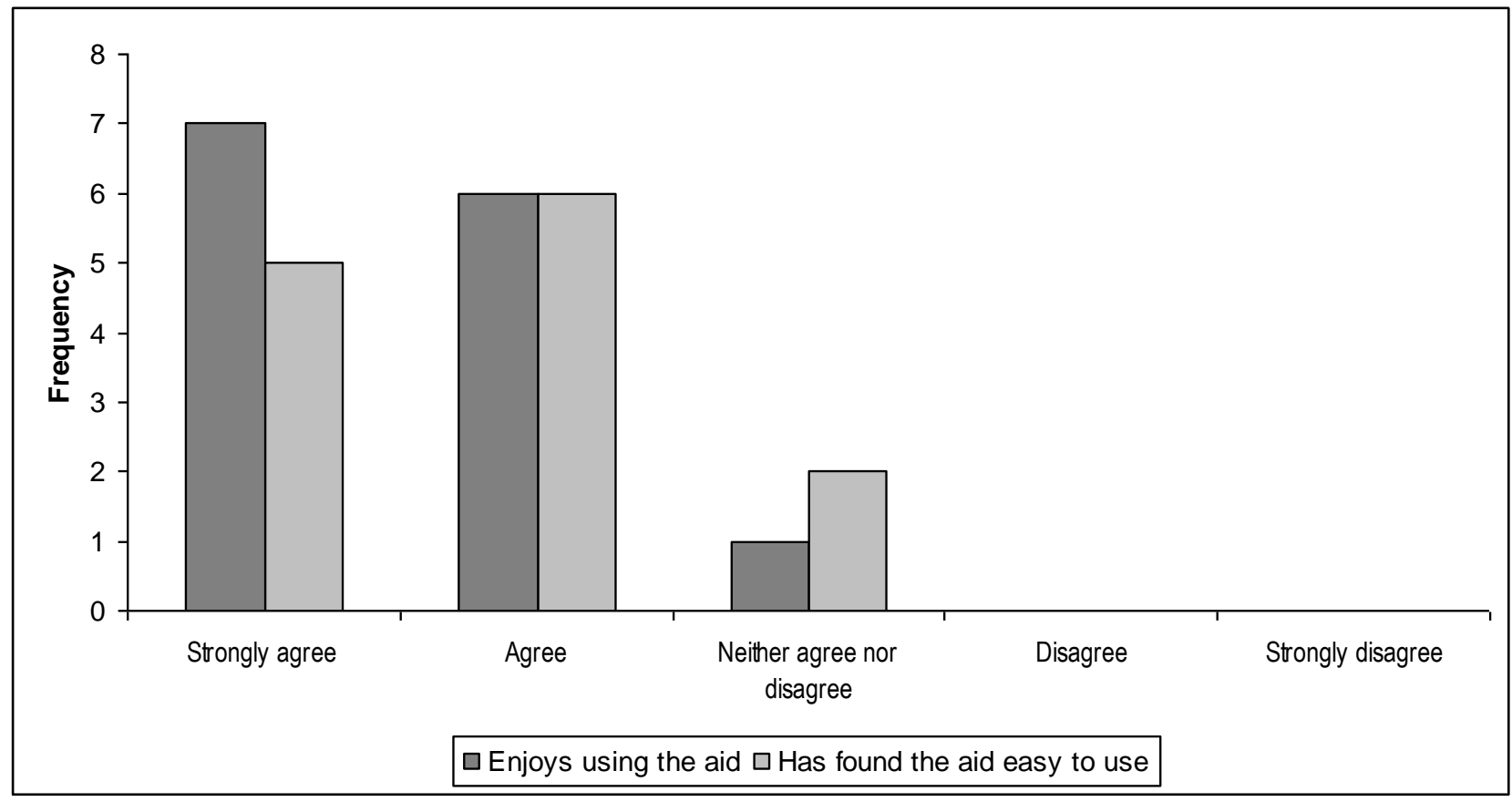


Figure 2. Parents' views on their child's interpersonal relationships

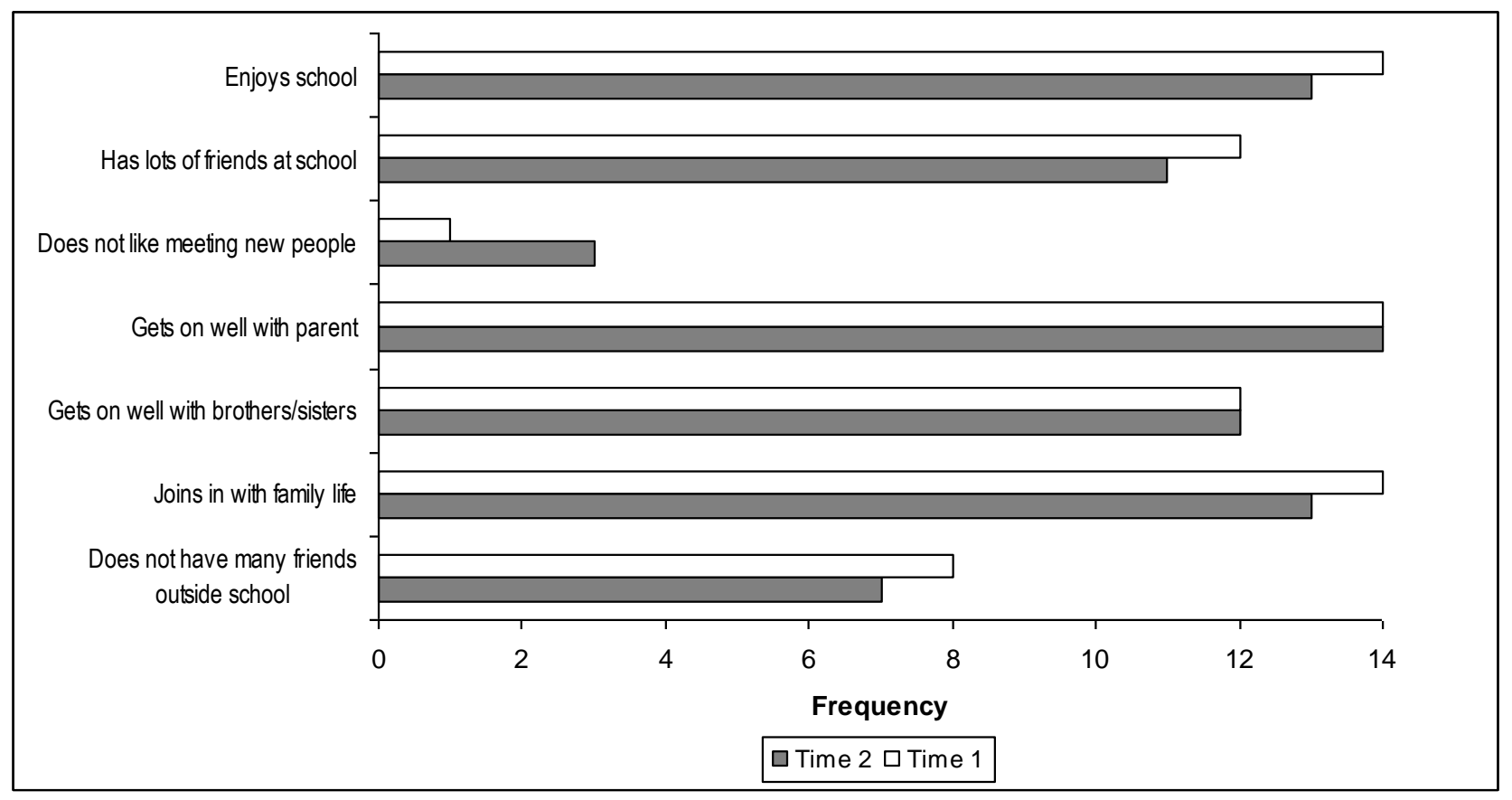


Figure 3. Parents' views on the CAP process

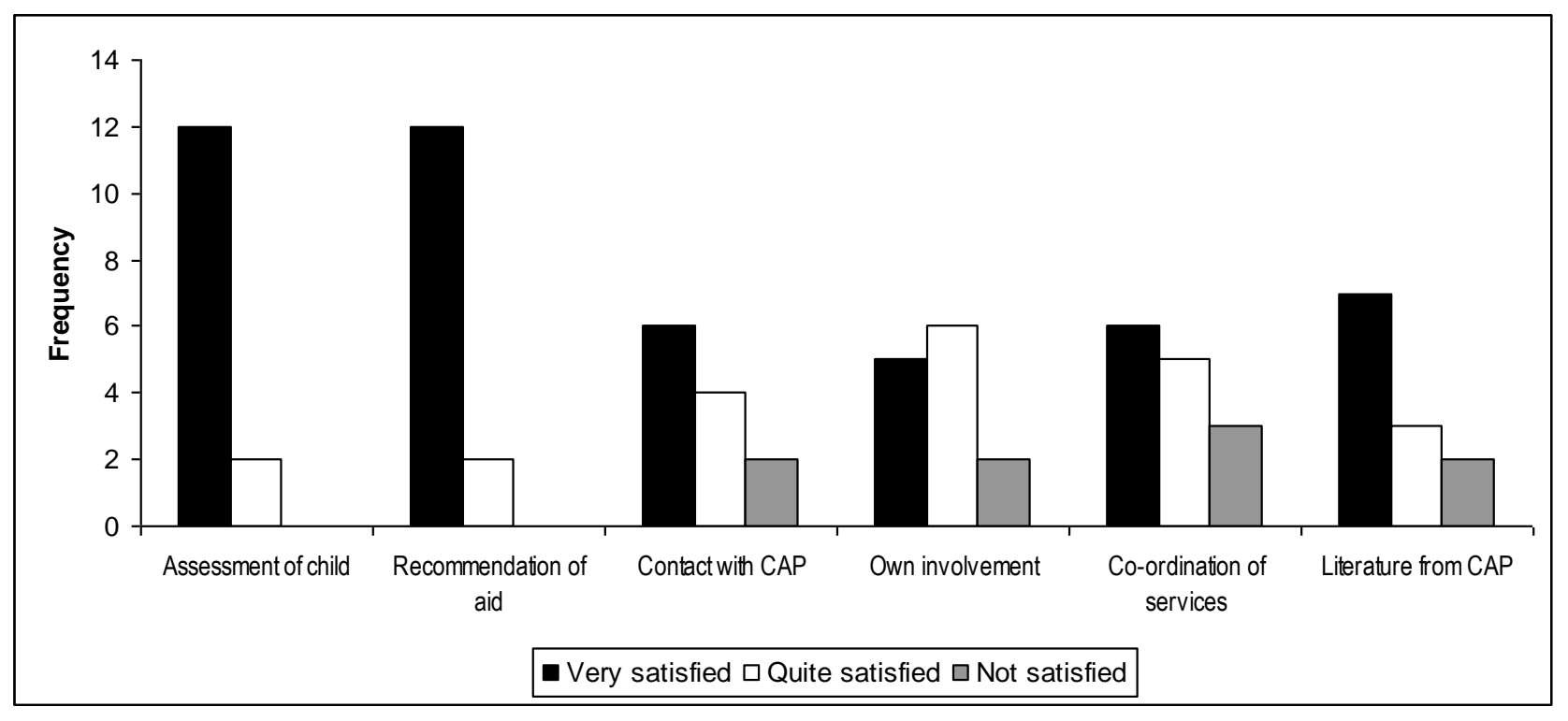


Appendix 1. Interview checklist for anticipated and current use of the communication aid Where the child will be/is using the aid

\begin{tabular}{|l|l|}
\hline Classroom & \\
\hline Playground & \\
\hline On the journey between home and school & \\
\hline Home & \\
\hline Garden at home & \\
\hline Other (please specify) & \\
\hline
\end{tabular}

What the child will be/is using the aid for

\begin{tabular}{|l|l|}
\hline Talking to the teacher & \\
\hline Talking to friends at school & \\
\hline Talking to friends outside school & \\
\hline Planning work & \\
\hline Writing answers to school work & \\
\hline Writing essays & \\
\hline Taking notes & \\
\hline Checking spelling & \\
\hline Involvement in extra curricular activities & \\
\hline Talking to you & \\
\hline Talking to other family members & \\
\hline Talking to new/unfamiliar people & \\
\hline Other (please specify) & \\
\hline
\end{tabular}

